\title{
Familial amyloid polyneuropathy (TTR ala 60) in north west Ireland: a clinical, genetic, and epidemiological study
}

\author{
M M Reilly, H Staunton, A E Harding
}

\begin{abstract}
A cluster of cases of familial amyloid polyneuropathy has been described in Donegal, north west Ireland. Two patients from this region have been shown to have the ala 60 mutation in the transthyretin gene. Three kindreds with this mutation have also been described in the United States. Genealogical and haplotype studies indicate that all known patients with this mutation are related and are descended from a founder in north west Ireland. There is evidence for reduced penetrance of this disorder. A population based study showed that $1 \cdot 1 \%$ of the population in this area in north west Ireland carry the mutation. This has implications in terms of diagnosis, genetic counselling, and treatment in the future.
\end{abstract}

\section{(F Neurol Neurosurg Psychiatry 1995;59:45-49)}

Keywords: familial amyloid polyneuropathy; amyloid; transthyretin

Familial amyloid polyneuropathy (FAP) is an autosomal dominant disorder most commonly caused by the deposition of variant transthyretin (TTR) in affected tissues. ${ }^{1}$ It was originally described by Andrade in Portuguese kindreds in $1952^{2}$ and subsequently the variant TTR responsible for the Portuguese cases was found to have a substitution of methionine for valine at position $30 .^{3}$ There are now at least 27 point mutations in the TTR gene associated with peripheral neuropathy (as opposed to non-neuropathic amyloidosis). ${ }^{4}$ The commonest clinical features are those of a small fibre neuropathy with autonomic dysfunction and cardiomyopathy, with vitreous and renal involvement occurring less often. Some mutations have characteristic, although not distinguishing, clinical features.

In 1987, Staunton and colleagues described a cluster of eight patients with FAP from seven families in a small area of Donegal in north west Ireland. ${ }^{5}$ These cases were originally thought to have the Portuguese type of FAP, but certain clinical features, including the late age of onset, the predominance of the cardiomyopathy and a neuropathy affecting all fibre types, were not typical of that mutation. In 1991 two further patients from Donegal (including a first cousin of one of the original cases) were found to have the TTR ala 60 mutation, ${ }^{6}$ originally described in a family from the Appalachian region of the United States ${ }^{7}$ and more recently reported in two further American kindreds. ${ }^{89}$ The Appalachian kindred and one of the other American kindreds are Irish in origin ${ }^{8}$ (A Koeppen, personal communication); the origin of the third kindred is not known. In the initial report by Staunton and colleagues, 5 only four of the eight patients gave a history of affected relatives, and it could not be assumed that all the cases had a genetic basis and if so, whether all the patients had the same disease. If this were the case, it seemed clear that the disorder exhibited reduced penetrance.

We have re-examined all known families with presumed FAP in Donegal and have analysed the TTR gene for the ala 60 mutation in patients and selected relatives. We have also attempted to confirm the suspicion that all these patients, and those reported in the United States, are descended from a common founder by extended pedigree and haplotype analysis. Finally, we carried out a population based study in the particular area of Donegal involved to assess the prevalence of gene carriers among persons not known to be at risk of FAP.

\section{Patients and methods}

PATIENTS

The details of the index cases of six of the original families (one index case was illegitimate and no further information was available) and the more recently described family were available to us from earlier studies. ${ }^{56}$ By contacting and later visiting these families and their relatives, and also the only remaining living patient from earlier studies, we were able to extend the pedigrees originally presented. ${ }^{56}$ We also obtained information from the official local marriage register, which extends back to 1860. All earlier public records relating to pedigrees in Ireland were destroyed in a fire in 1916. Useful information on the origin of surnames came from a special report on the surnames of Ireland from $1909^{10}$ and from a book on Ulster surnames. ${ }^{12}$

To study the penetrance of the TTR ala 60 gene, we interviewed all the relatives of the original patients whom we could trace in Ireland and England. With ethics committee approval and informed consent these were visited by one of us (MMR). A full clinical general and neurological examination was performed, with special attention to the cardiovascular system and motor and sensory function in the limbs, and a blood sample was 


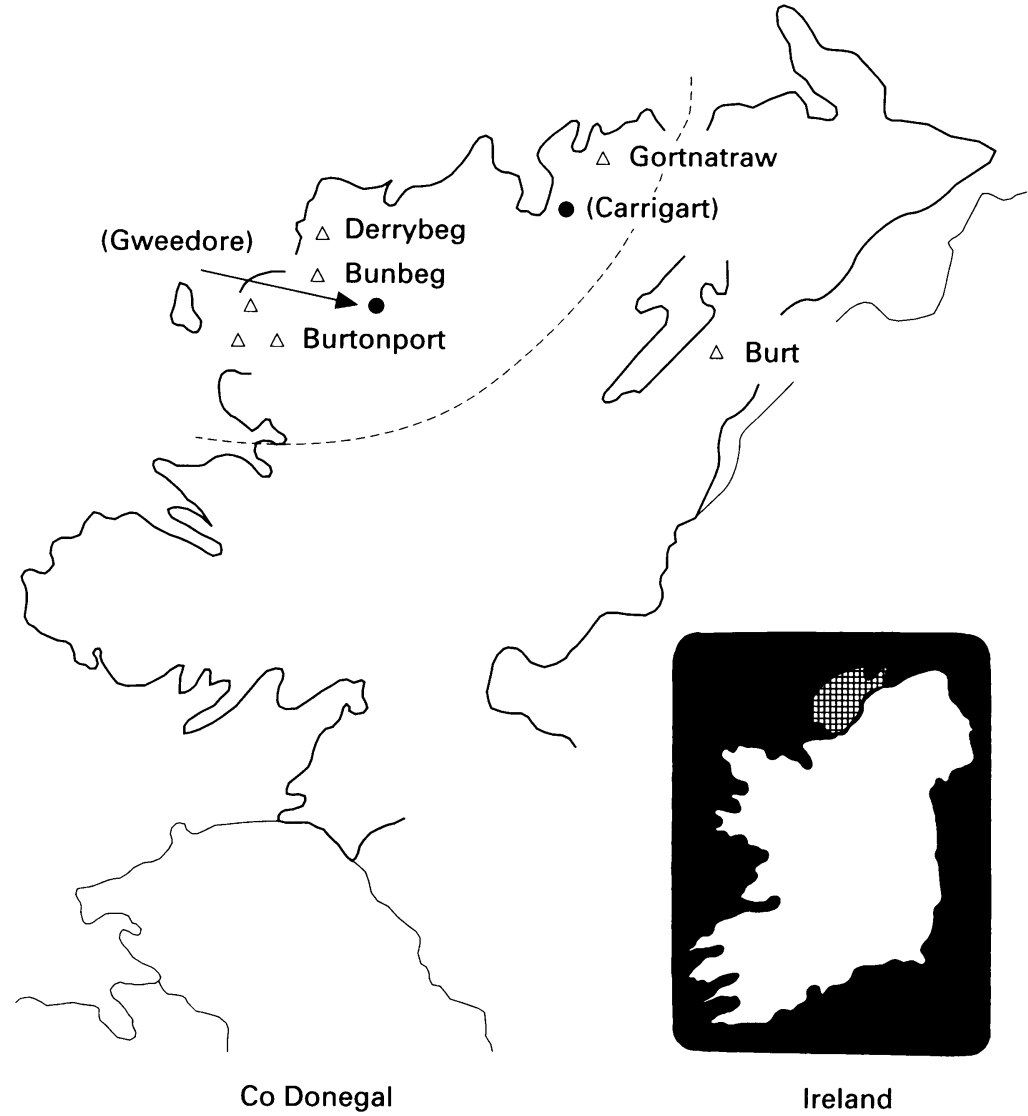

Figure 1 Map of part of county Donegal (county hatched on map of Ireland in lower right of figure) showing the distribution of the seven original families with TTR ala 60 related FAP (open triangles) and the area from which the random sample of the population was selected (to the left of broken line). Modified from Staunton et a $\bar{\Gamma}$ with permission. taken. We only screened relatives over the age of 40 as these were the only ones likely to have an asymptomatic neuropathy due to the ala 60 TTR mutation in view of the late onset of TTR ala 60 FAP. ${ }^{56}$ In total we screened 28 relatives.

For the population based prevalence study, we screened 182 people over the age of 40 who were resident in the area from which all the original patients originated (fig 1). These were ascertained from people attending local general practitioner's surgeries and the local hospital outpatient department who did not have cardiac or neurological symptoms (as these could be due to FAP) or a family history of amyloidosis. This age group was again selected so that subjects found to have the TTR ala 60 gene could be included in the

Table 1 Oligonucleotide primers

\begin{tabular}{llll}
\hline & No & Position & Sequence \\
\hline PCR primers: & & & \\
Exon 3 & 719 & $3785-3804$ & 5'-CTCCATGCGTAACTTAATCC-3' \\
Exon 3 & 718 & $4359-4340$ & 5'-GCCAGATGTGTTTTGGAATG-3' \\
Haplotype & & & \\
primers: & & & \\
Intron 2 & A5 & $2402-2411$ & 5'-ACGATCACCCGACTTCATGT-3' \\
Intron 2 & A6 & $2563-2543$ & 5'-AAGGGTCTCCTGATTGCTCTG-3' \\
Intron 3 & A3 & $5572-5591$ & 5'-AATGCCTCACTTTGGTGACG-3' \\
Intron 3 & A9 & $5733-5714$ & 5'-GAGGCCTAAGAGCTCCTAGT-3' \\
\hline
\end{tabular}

Underlining indicates mismatch site. penetrance study. The screening procedure was the same as that in relatives, consisting of clinical examination and TTR gene analysis. Results were not given to either relatives or the participants in the population study, and they gave consent on this basis.

\section{DNA ANALYSES}

DNA was extracted from blood by standard methods. The TTR mutation underlying the ala 60 variant creates a new restriction site for the restriction endonuclease Pvu II. Genomic DNA was amplified by polymerase chain reaction (PCR) and primers flanking TTR exon 3 (table 1: primers 718 and 719 ), using a Hybaid Intelligent heating block and Taq polymerase (Promega). Amplification was carried out for 30 cycles, comprising denaturing at $90^{\circ} \mathrm{C}(30 \mathrm{~s})$, annealing at $50^{\circ} \mathrm{C}(30 \mathrm{~s})$, and elongation at $70^{\circ} \mathrm{C}(30 \mathrm{~s})$. Products of PCR were digested with Pvu II (Promega) under conditions recommended by the manufacturers. The digested products were electrophoresed in a $3.2 \%$ agarose gel (BCR), stained with ethidium bromide, and visualised with ultraviolet light.

There are seven polymorphisms in introns of the TTR gene and five different haplotypes designated I-V have been described..$^{12}$ A haplotype has been published using six of the seven TTR polymorphisms for one of the American cases with FAP ala 60 (the one whose ancestry is not clear; Ii S, Sommer SS, presentation at PNA meeting, Rapallo, 1992) and this corresponds to haplotype I with Yoshioka's nomenclature. ${ }^{12}$ We analysed polymorphisms 3,5 , and $6^{12}$ to determine the haplotypes of our patients with TTR ala 60 and also 49 control subjects from the population study who did not have the mutation. Polymorphism 3 is an $\mathrm{A} / \mathrm{G}$ polymorphism in the second intron of the TTR gene, and polymorphism 5 and $6 \mathrm{G} / \mathrm{C}$ and $T / \mathrm{G}$ polymorphisms in the third intron. Polymorphisms 3 and 5 are detected by $M s p$ I and $F n u 4 \mathrm{H} 1$ restriction, using PCR with primers A5 and A6 and A3 and A9 (table 1) respectively. Conditions were as used for the exon 3 primers except that the annealing temperature was $56^{\circ} \mathrm{C}$ for polymorphism 3 and 5 . The PCR products were digested with Msp I (Promega) or Fnu 4HI (New England Biolabs) respectively.

Polymorphism 6 was detected by mismatch PCR using primers A3 and A9 (table 1), the last creating a single mismatch of $G$ for $A$ near the $3^{\prime}$ end so that the PCR product contains a new restriction site for Rsa I only when G and not $T$ is present at polymorphism 6 . The PCR conditions were as for polymorphism 5 , with subsequent digestion with $R s a$ I (Promega).

\section{Results}

Only two affected patients from the seven previously described families (excluding that of the illegitimate patient) were still alive, one reported by Staunton $e t a l^{6}$ and the other a 64 year old man with onset of paraesthesiae and numbness in his hands and feet when aged 
Family A

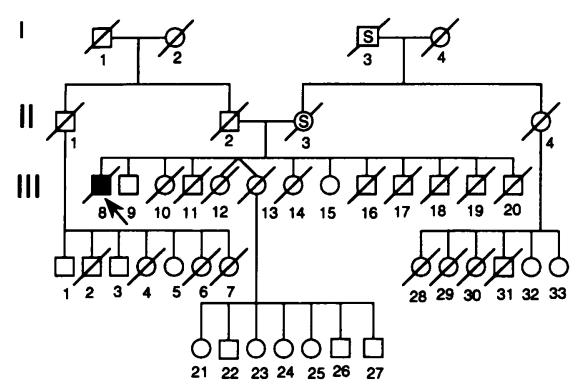

Family C

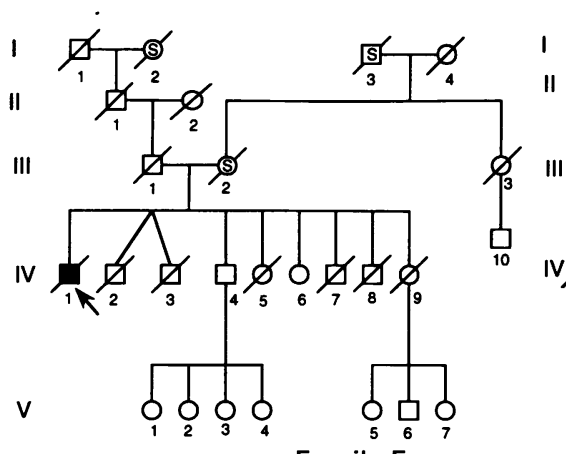

Family E

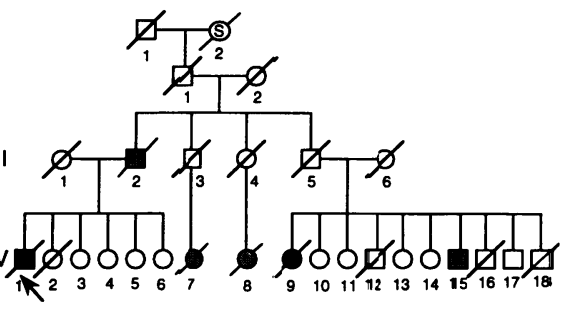

Family $\mathrm{F}$

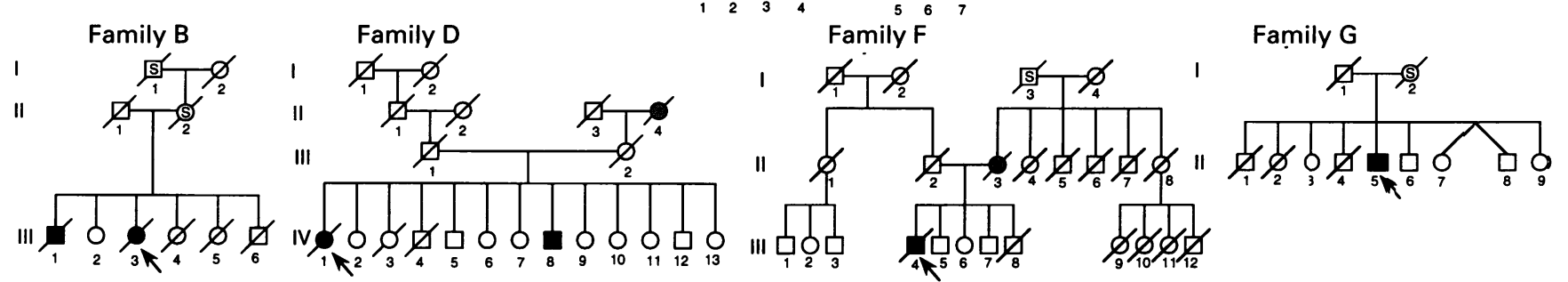

Figure 2 Pedigrees of ala 60 families. Arrow = index case; square symbols = male; circle = female; oblique lines = deceased; filled symbols = affected; open = unaffected; hatched $=$ probably affected; $S=$ common surname. Index cases of families $A, B, C, D, E$, and $F$ are cases $2,1,4,5,6$, and 7 respectively in Staunton et al. ${ }^{5}$

61. He was a brother of the index case in one of the original families (case 5). ${ }^{5}$ No new families were identified. Figure 2 shows the pedigrees. Of the definitely affected patients, eight were men and four were women, with a median age of onset of symptoms of 61.5 (range 56-66) years and age of death 66 (range 59-78) years. DNA analysis confirmed the presence of TTR ala 60 (in either patients or relatives) in families $D, E$, and $G$. This was not confirmed or excluded in families A-C and $F$ as no tissue was available from the index cases. In the seven pedigrees studied, the mutation seemed to be inherited from the mother in five cases (families A, B, C, F, and $\mathrm{G})$, from the father in one case (family $E$ ), and in the last family (family D) the inheritance pattern was not clear.

By extending the pedigrees of the seven families (fig 2) we found that six had an ancestral surname in common. Because the age of onset of the disease is so late and the neuropathy was often overlooked, it was difficult to get an accurate history concerning dead relatives who were probably affected. In two of these six families, relatives outside the index sibship had died of an undiagnosed illness clinically similar to FAP and dominated by features of neuropathy or cardiomyopathy. These relatives were all descended from a person with the common ancestral surname (families E and F, fig 2). This surname (not disclosed for reasons of confidentiality) is frequent in northern Ireland and was present in either the maternal or paternal ancestors of five families, and both in one (family C). The original family with this name was descended from a man called Conall Gulban, after whom the county Donegal (previously known in Gaelic as Tír Chonall, meaning land of Conall), is named." The only family without the common surname is family $\mathrm{D}$. The maternal grandmother in this family, who came from county Derry, had a very similar illness to the index case.

Eight asymptomatic gene carriers for the TTR ala 60 mutation were initially found from the 28 relatives screened (not indicated in fig 2 for reasons of confidentiality). Eighteen months after starting this study, one of these eight became symptomatic with painful paraesthesiae in his upper and lower limbs. He was clinically normal at the time of the study. There were also five obligate asymptomatic gene carriers within the pedigrees, all of whom were dead.

In the population prevalence study two of the 182 subjects (all aged over 45) screened were found to be asymptomatic carriers of the ala 60 mutation. The total population of the area screened was 16414 and 3200 were over the age of $45 .{ }^{14}$ Thus the predicted frequency of asymptomatic gene carriers in the population over 45 was $1 \cdot 1 \%$ with a $95 \%$ confidence interval $(95 \% \mathrm{CI})$ of $0.3-2.3 \%$ and the predicted number of gene carriers in the same population was 35 (95\% CI 10-74). The median age or age of death of the 10 asymptomatic TTR ala 60 carriers (eight relatives and two from the random population 45 or over) and the five deceased obligate gene carriers was 61 (range 45-74) years. Two were aged in the range $45-49$, four $50-54$, one $55-59$, three 60-64, three 65-69, and two 70-74. Thus seven of the asymptomatic and obligate gene carriers were older than the median age of onset of patients with FAP (61.5 (range 56-66) years).

Table 2 summarises the results of haplotype analysis of nine members from seven families with the mutation. Seven were homozygous for haplotype I, suggesting that this haplotype is associated with the mutation. The other two were heterozygous for haplotype I, one with haplotype II, and one with haplotype III. Of the 49 controls from the 
Table 2 Haplotype analysis of nine patients with FAP ala 60

\begin{tabular}{|c|c|c|c|c|}
\hline \multirow[b]{2}{*}{ Patient } & \multicolumn{3}{|c|}{ TTR Polymorphism } & \multirow[b]{2}{*}{ Haplotype } \\
\hline & 3 & 5 & 6 & \\
\hline $\begin{array}{l}1 \\
2 \\
3 \\
4 \\
5 \\
6 \\
7 \\
8 \\
9\end{array}$ & $\begin{array}{l}\text { A } \\
\text { A } \\
\text { A } \\
\text { A } \\
\text { A } \\
\text { A } \\
\text { A } \\
\text { A/G }\end{array}$ & $\begin{array}{l}G \\
G \\
G \\
G \\
G \\
G \\
G \\
G \\
G \\
G / C\end{array}$ & $\begin{array}{l}\mathrm{T} \\
\mathrm{T} \\
\mathrm{T} \\
\mathrm{T} \\
\mathrm{T} \\
\mathrm{T} \\
\mathrm{T} \\
\mathrm{T} \\
\mathrm{T} / \mathrm{G}\end{array}$ & $\begin{array}{l}\text { I } \\
\text { I } \\
\text { I } \\
\text { I } \\
\text { I } \\
\text { I } \\
\text { I } \\
\text { I/II }\end{array}$ \\
\hline
\end{tabular}

Polymorphism 3: $161 \mathrm{bp}$ product restricted to fragments of $133 \mathrm{bp}$ and $28 \mathrm{bp}$ if $\mathrm{G}$, not $\mathrm{A}$; polymorphism 5: 163 bp product restricted to $132 \mathrm{bp}$ and $31 \mathrm{bp}$ if $\mathrm{G}$, not $\mathrm{C}$; polymorphism 6 : $163 \mathrm{bp}$ product restricted to $142 \mathrm{bp}$ and $21 \mathrm{bp}$ if $\mathrm{G}$, not $T$.

same area who did not have the mutation, $30 \%$ were homozygous for haplotype I, $4 \%$ were homozygous for haplotype III, and the remainder were heterozygous for at least one of the three polymorphisms, including 55\% for haplotype I. The prevalence of haplotype I in the patients was significantly higher than in controls $\left(\chi^{2}=4.9\right.$ (with Yates' correction), $\mathrm{P}=0.027)$.

\section{Discussion}

Although we have not been able to link the pedigrees of the seven Donegal families directly, the existence of a common surname in six of the families, and the demonstration that all the TTR ala 60 positive subjects share a common haplotype (haplotype I) strongly suggests that they are related. Although we did not find any evidence that family $D$ is related to the other families, this remains a strong possibility. TTR ala 60 positive family members from family $\mathrm{D}$ also had haplotype $\mathrm{I}$. The affected grandmother in family D came from Derry in Northern Ireland; the founder of the original Appalachian family with FAP TTR ala $60^{7}$ emigrated from Derry in the early 19th century (MD Benson, personal communication). Although this founder's name is not known, Derry is one of the counties outside Donegal (geographically adjacent) where our families' common ancestral surname is mainly found. ${ }^{10}$ The founder of one of the other American families ${ }^{8}$ was born in New York in 1862 and both his parents were from Ireland (AH Koeppen, personal communication). Affected members of the third kindred of unknown ancestry have been shown to share the same haplotype found in all of our patients. This evidence collectively suggests that all known cases of FAP associated with the TTR ala 60 mutation are descended from a common founder in north west Ireland. As two of the American kindreds emigrated from Ireland in the early 19 th century the mutation must have occurred before then.

Since the early 19 th century there has been mass emigration from Donegal, particularly to Glasgow in Scotland, England, the United States, and Canada. It is therefore to be expected that cases will be described in Scotland and Canada and further cases in England and the United States. We are aware of a patient, with ancestors from Donegal, in Australia who has the ala 60 mutation (A Colley, personal communication). Haplotype studies have strongly suggested that the commonest TTR mutation (TTR met 30) associated with FAP has multiple founders ${ }^{12} 1315$ and there is also some evidence to suggest that the TTR tyr 77 mutation may have more than one founder. ${ }^{1516}$ Most of the other mutations have been described in single families. The TTR ala 60 families represent the second largest group of families with a common mutation from different areas (Ireland, England, and the United States) to be traced to a common founder, the largest being those of known Portuguese origin with FAP TTR met 30 .

It proved difficult to calculate accurate penetrance values for the TTR ala 60 mutation from our limited data. It has been estimated previously that the penetrance for the TTR met 30 mutation is about $80 \% .{ }^{16}$ This is obviously very important for genetic counselling. In our study the median age of onset of FAP TTR ala 60 was 61.5 years and the median age or age at death of the asymptomatic and obligate carriers respectively was 61 years. Seven of the asymptomatic or obligate carriers were older than the median age of onset of the affected patients. Five obligate carriers had died unaffected aged 45-74 years. These findings and the pedigree data suggest reduced penetrance, but calculation of accurate penetrance values will require data from more kindreds and follow up of our asymptomatic carriers over the next 10 to 20 years. There were more affected men than women in this series; this is also true in the large Appalachian kindred. ${ }^{7}$ It is possible that penetrance is partly sex dependent.

From this study we can estimate that about $1 \%$ of the population over 45 in a small area of Donegal (fig 1) carry the TTR ala 60 mutation. The sample size was small and therefore the confidence intervals of this estimate were wide. If $1 \%$ of the population over the age of 45 have the mutation it is likely that this proportion also applies to the total population in this area, because the population is relatively fixed with some emigration from, but very little immigration into, the area. The total population of the area is 16414 . The predicted number of subjects with the TTR ala 60 mutation in this area is 181 (95\% CI $49-378)$. Even assuming penetrance substantially less than $100 \%$, this suggests that there will be a substantial number of patients with FAP ala 60 presenting in this area over the coming years. It is notable that, over the two years since starting this study, we identified four more cases of FAP ala 60, one of whom was originally detected as an asymptomatic carrier in one of the families, another from the area we studied, and two cases from surrounding areas.

The number of future patients with FAP ala 60 and the ease with which they can now be diagnosed genetically is even more important with the emergence of a potential treatment. Because $90 \%$ of TTR is produced in 
the liver, liver transplantation has been used as a treatment for FAP met 30 . Initial studies showed that after liver transplantation only normal TTR could be detected in plasma. ${ }^{18}$ Two year follow up of the first four patients transplanted showed that general well being and autonomic function improved and the peripheral neuropathy seemed to arrest with no further deterioration. ${ }^{19}$ Further studies are needed to confirm this, and to determine long term outcome and the optimum time for transplantation. It is suggested that patients should be transplanted early as many of the complications are related to the severity of autonomic neuropathy. We are aware of one patient with TTR met 30 who died in the postoperative period because of advanced autonomic failure (unpublished data). It might be difficult to justify liver transplantation in FAP ala 60 given that onset is consistently late. The associated cardiomyopathy might require combined cardiac and liver transplantation, which has been performed in a patient with the tyr 77 mutation. ${ }^{19}$ The available evidence suggests that FAP TTR ala 60 will become a medical problem of substantial socioeconomic importance in forthcoming years in this area of Donegal.

We thank Dr Mary Davis and Cathy Woodward for assistance with the DNA analyses, the Donegal county physicians, Dr
Brian Callaghan and Dr Liam Bannon, and the many local Brian Callaghan and Dr Liam Bannon, and the many local
general practitioners who provided valuable assistance in contacting patients' relatives and enlisting subjects for the population study, Tomás ó Baoill for his help in constructin pedigrees and tracing the origin of surnames, and all the families in Donegal and elsewhere for their invaluable assistance with this project. Dr Mary Reilly was supported by a grant from the Royal College of Physicians of Ireland and Glaxo, Ireland.

1 Costa P, Figueira AS, Bravo RR. Amyloid fibril protein related to pre-albumin in familial amyloidotic polyneuropathy. Proc Natl Acad Sci USA 1978;75:4499-503.

2 Andrade C. A peculiar form of peripheral neuropathy Familial atypical generalised amyloidosis with specia involvement of the peripheral nerves. Brain 1952;75: 408-27.

3 Saraiva MJM, Birken S, Costa PP, Goodman DS. Amyloid fibril protein in familial amyloidotic polyneuropathy, Portuguese type. $\mathcal{f}$ Clin Invest 1984;74:104-19.

4 Reilly M, King RHM. Familial amyloid polyneuropathy. Brain Pathology 1993;3:165-76.

5 Staunton H, Dervan P, Kale R, Linke RP, Kelly P. Hereditary amyloid polyneuropathy in north west Ireland. Brain 1987;110:1231-45.

6 Staunton $H$, Davis MB, Guiloff RJ, Nakazato M, Miyazato N, Harding AE. Irish (Donegal) amyloidosis is associated with the transthyretin ${ }^{\text {Ala } 00}$ (Appalachian) variant. Brain 1991;114:2675-9.

7 Benson MD, Wallace MR, Tejada E, Baumann $H$, Burnestine P. Hereditary amyloidosis: description of a new American kindred with late onset cardiomyopathy. Arthritis Rheum 1987;30:195-200.

8 Koeppen AH, Wallace MR, Benson MD, Altland K. Familial amyloid polyneuropathy: alanine-for-threonine substitution in the transthyretin (prealbumin) molecule. Muscle Nerve 1990;13:1065-75.

9 Ii S, Minnerath S, Ii K, Dyck PJ, Sommer SS. Two-tiered DNA-based diagnosis of transthyretin amyloidosis reveals two novel point mutations. Neurology 1991;41: reveals $893-8$.

10 Matheson RE (Registrar General for Ireland). Surnames of Ireland, varieties and synonymies, Special report: 1909

11 Bell R. The book of Ulster surnames. Belfast. St. Pauls Minnesota: Blackstaff Press, 1988.

12 Yoshioka K, Furuya H, Sasaki H, Saraiva MJM, Costa PP, Sakaki Y. Haplotype analysis of familial amyloidotic polyneuropathy. Hum Genet 1989;82:9-13.

13 Ii S, Sommer SS. The high frequency of TTR $\mathrm{Met}^{30}$ in familial amyloidotic polyneuropathy is not due to a founder effect. Human Molecular Genetics 1993;2: 1303-5.

14 Census of Population of Ireland (1986) Local population report: 1 st series No 27. Co Donegal: CPI, 1986.

15 Reilly MM, Adams D, Davis MB, Said G, Harding AE. Haplotype analysis of French, British, and other European patients with familial amyloid polyneuropathy European patients with familial amyloid
(met 30 and tyr 77). $\mathscr{F}$ Neurol (in press).

16 Benson II MD, Turpin JC, Lucotte G, Zeldenrust S, LeChevalier B, Benson MD. A transthyretin variant (alanine II) associated with familial amyloidotic polyneuropathy in a French family. $\mathcal{F}$ Med Genet 1993;30: $120-22$.

17 Sequeiros J, Saraiva MJM. Onset in the seventh decade and lack of symptoms in heterozygotes for the TTR ${ }^{\text {Met30 }}$ mutation in hereditary amyloid polyneuropathy-type 1 (Portuguese, Andrade). Am 7 Med Genet 1987;27: 345-57.

18 Holmgren G, Steen L, Ekstedt J, Groth C-G, et al. Biochemical effect of liver transplantation in two Swedish patients with familial amyloidotic polyneuropathy (FAP-Met 30) Clin Genet 1991;40:242-6.

19 Holmgren G, Ericzon B-G, Groth C-G, Steen L, et al. Clinical improvement and amyloid regression after liver transplantation in hereditary transthyretin amyloidosis Lancet 1993;341:1113-6. 